\title{
Optimization of degradation of ciprofloxacin antibiotic and assessment of degradation products using full factorial experimental design by Fenton Homogenous process
}

\author{
Rakhshandehroo G.R., Salari M. ${ }^{*}$ and Nikoo M.R. \\ Department of Civil and Environmental Engineering, Shiraz University, Shiraz, Iran \\ Received: 29/11/2017, Accepted: 03/02/2018, Available online: 21/05/2018 \\ *to whom all correspondence should be addressed: e-mail: m.salari@shirazu.ac.ir
}

\begin{abstract}
The Pharmaceutical contaminants specialist antibiotics into environment can create problems for both human health and environment. Ciprofloxacin (CIP), an antibiotic Fluoroquinolones group, has recently been used widely for infections treatment. The main purpose of the research was to develop a Full factorial method for degradation of $\mathrm{CIP}$ in aqueous solution by Fenton Homogenous process $\left(\mathrm{Fe}^{2+} / \mathrm{H}_{2} \mathrm{O}_{2}\right)$. In order to compare the effects of the four parameters considered in the optimization of the oxidative process, a two level Full factorial experimental design $\left(2^{4}\right)$ was utilized using $\mathrm{JMP}^{\circledR}$ software. These parameters were concentration of CIP $\left(X_{1}\right)$, concentration of $\mathrm{Fe}^{2+}\left(X_{2}\right)$, concentration of $\mathrm{H}_{2} \mathrm{O}_{2}\left(X_{3}\right)$ and time $\left(X_{4}\right)$ at ambient temperature and an acidic $\mathrm{pH}$. In the optimal conditions of the initial concentration of CIP $10 \mathrm{mg} / \mathrm{l}, \mathrm{Fe}^{2+}$ concentration of $5 \mathrm{mM}$, and $\mathrm{H}_{2} \mathrm{O}_{2}$ concentration of $25.6 \mathrm{mM}$ degradation efficiency of CIP was $76 \%$ within $45 \mathrm{~min}$. Under these conditions, the highest correlation coefficient proved between observed and predicted degradation efficiencies with $R^{2}=0.996$ and $A d j-R^{2}=0.968$. The reaction intermediates have been identified by LC-MS and $\mathrm{BOD}_{5} / \mathrm{COD}$ ratio for study biodegradability enhanced from zero to 0.32 , showed that the Fenton Homogenous process was agreeable to biological treatment. Based on the results, this may be concluded that Fenton Homogenous process by Full factorial experimental design could be used to degrade CIP from aqueous solutions efficiently.
\end{abstract}

Keywords: Full factorial design, Degradation efficiency, Fenton Homogenous process, Ciprofloxacin antibiotic, Optimization

\section{Introduction}

Pharmaceutical residues are important issues to the environment, especially water resources, because they are stable and do not degrade in the environment, even in small concentrations or with low residual activities (Gagnon et al., 2008; Dirany et al., 2010). More specifically, antibiotics are important pharmaceutical pollutants which may enter water resources through pharmaceutical wastewater, hospital and veterinary clinics sewage, combined with domestic sewage, and effluents of agricultural product plants and fish ponds (Wynnae, 2003).

A big family of antibiotics widely used in disease treatments is Fluoroquinolones, which include Ciprofloxacin (CIP), Ofloxacin and Norfloxacin. The presence of fluorine atoms in the composition of these antibiotics has granted them stability, and therefore they have been considered as a serious contaminant into environment (Capriotti et al., 2012). In particular, CIP is a pharmaceutical antibacterial drug used worldwide in both human and animal medicine for bacterial infections (Zhang et al., 2015; Salari et al., 2018). Ineffective removal of CIP by conventional water treatment technologies and its subsequent discharge into the environment has granted its presence in surface water, groundwater, wastewater, and even plants (Han et al., 2015). Recent studies have shown that advanced of each new pharmaceutical drug mainly antibiotics imposes a potential danger for both human health and environment particularly, hydrology resources (Guo et al., 2013).

Due to poor biodegradability of CIP with biological methods, it looks important to utilize a treatment process that is capable of destroying residual CIP. It is essential to develop modern fast and cost-effective methods to treat pharmaceutical wastewaters (Salari et al., 2018). In fact, removal of this pollutant has been sought by many researchers utilizing many advanced oxidation processes (AOPs). AOPs are effective processes, based on formation of hydroxyl radical, that totally decompose organic and refractory compounds such as CIP to low molecular weight compounds (Pera-Titus et al., 2004). Lately, AOPs have been accepted as efficient methods used for degradation of toxic and environmentally-resisting organics compounds (Giri and Golder 2014; Bouasla et al., 2010). A literature survey shows that degradation efficiency of CIP has been investigated via HPLC ${ }^{1}$ and TLC (Krzek et al., 2005). UV and $\mathrm{UV} / \mathrm{H}_{2} \mathrm{O}_{2}$ by multiple-wavelength ultraviolet light-emitting diodes (Ou et al., 2016), Photo catalytic synthesized with 
$\mathrm{TiO}_{2}$ nanoparticles on montmorillonite (Hassani et al., 2015), UV $/ \mathrm{H}_{2} \mathrm{O}_{2} \quad$ (Baeissa, 2016), photo-Fenton Homogenous (Bobu et al., 2015), Sonolysis (De Bel et al., 2009), and adsorption processes (Jiang et al., 2009). Particularly, Fenton Homogenous processes have been used as one of the best methods to control and reduce organic pollutions, whereby inexpensive and environmentally friendly reagents are employed (Biglarijoo et al., 2016).

While degrading organic compounds, many different variables affect a Fenton Homogenous process such as speed of shaking, $\mathrm{pH}$ of the solution, concentration of hydrogen peroxide, volume of the solution, concentration of ferrous ions, contact time, and temperature (Elhalil et al., 2016). Studying effect of each factor separately and interaction of parameters would be quite very tedious and time consuming. Factorial experimental design has been utilized to minimize the above problems with optimizing all affecting parameters collectively at one time (Wang et al., 2010). The design determines the effect of each factor, and interacting effects of the parameters on the response, as well as how the effect of each factor varies with a change in the level of other factors (Arenas et al., 2006). It is known that interaction effects of different factors may be attained only by design of experiments, and factorial method may be applied to reduce the number of experiments, time of experiments, overall process cost, and to achieve a better response (Barka et al., 2014).

In previous studies, most researchers concentrated on evaluating AOPs for degradation of antibiotics, but experimental optimization using Full factorial method and Fenton Homogenous process particularity For CIP antibiotic has been never reported. In this work, an optimization has been done using a $2^{4}$ factorial experimental design. The full factorial was designed with four factors of two levels. The effects of each factor and their interaction are studied. The main purpose Fenton reaction as a pretreatment method is to improve the $\mathrm{BOD}_{5} / \mathrm{COD}$ ratio; thus, the ratio was measured after degradation in optimal condition to estimate the biodegradability rise and intermediates (by-products) were identified by HPLC coupled with a Mass Spectrometer analyses (LC-MS).

\section{Materials and methods}

\subsection{Chemicals and reagents}

Ciprofloxacin is an antibiotic compound belonging to a group of drugs called Fluoroquinolones, whose structural formula is presented on Fig. 1 (Kassab et al., 2005; Xiong et al., 2017).

All reagents used in all experiments had analytical grades. CIP was purchased from a local supplier called Shiraz Serum pharmaceutical company. Its Physico-chemical properties are listed in Table 1.

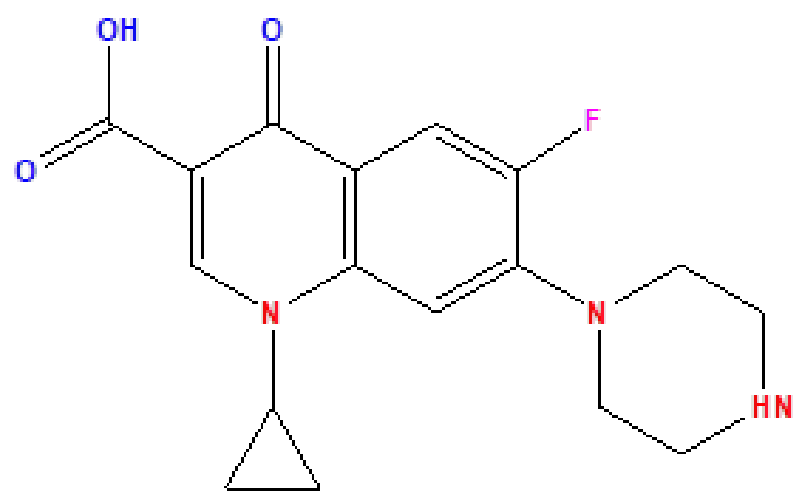

Figure 1. Structural formula of Ciprofloxacin (IUPAC name: 1-cyclopropyl-6-fluoro-4-oxo-7-(piperazin-1-yl)-quinoline3-carboxylic acid) (Kassab et al., 2005; Xiong et al., 2017)

Distilled water utilized as the solvent to prepare all solutions. A stock standard solution of Ciprofloxacin (500 $\mathrm{mg} / \mathrm{l}$ ) was prepared by suitable dilution of $2 \mathrm{ml} \mathrm{HCl}$. Ferrous sulfate $\left(\mathrm{FeSO}_{4}-7 \mathrm{H}_{2} \mathrm{O}\right)$, sulfuric acid $\left(\mathrm{H}_{2} \mathrm{SO}_{4}(95-7 \%)\right)$, Sodium hydroxide $(\mathrm{NaOH})$ and Hydrogen Peroxide $\mathrm{H}_{2} \mathrm{O}_{2}(30 \%)$ were all purchased from Merck Company.

Table 1. Physical-chemical properties of Ciprofloxacin (Xiong et al., 2017)

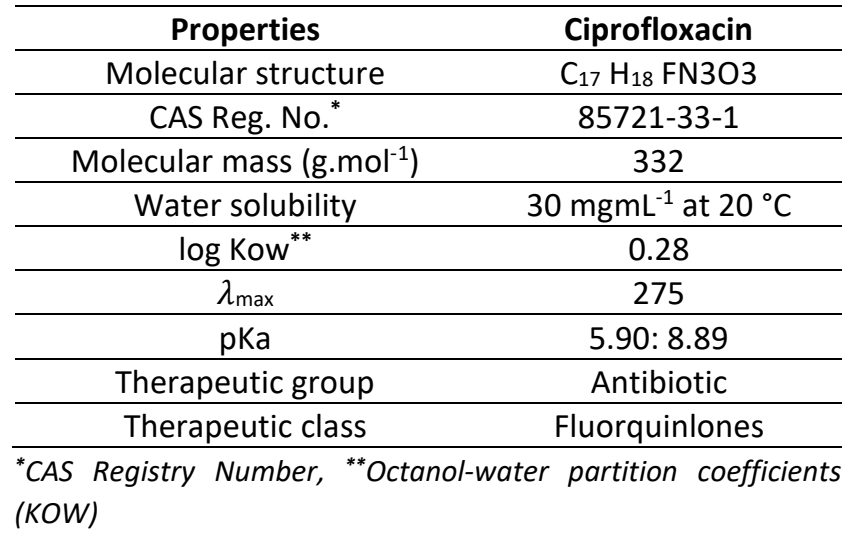

\subsection{Utilized devices}

Most analytical methods and researches use HPLC for determination of CIP concentration in solutions. Also, some researchers have reported use of UV or fluorescence for determination of CIP concentrations (Carlucci, 1998; Wright et al., 2000; Yorke and Froc, 2000). Recently, some studies have reported employing UV-Visible detection for various contaminants (Wright et al., 2000; Kamberi et al., 1998; Maya et al., 2001; Abdennouri et al., 2010). Use of UV-Visible has several advantages, compared to HPLC, such as simplicity, quickness and surely cheaper instrumentation. In this work, all absorbance and concentration measurements were made by a Hach UVVisible spectrophotometer model no. DR-5000 with $4 \mathrm{ml}$ matched quartz cells.

\subsubsection{HPLC/MS}

Identification of primary intermediates were recognized by a system of liquid chromatography coupled with a mass spectrometer (LC-MS) (Waters Alliance 2695 HPLCMicromass Quattro micro API Mass Spectrometer equipped with a Eclipse XDB-C18 $5 \mu, 4.6 \times 150 \mathrm{~mm}$ ). 
The mobile phase was composed of water containing $0.1 \%$ formic acid ( $\mathrm{v} / \mathrm{v})$ and acetonitrile containing $0.1 \%$ formic acid $(\mathrm{v} / \mathrm{v})$ and the flow rate was $0.5 \mathrm{~mL} / \mathrm{min}$. The injection volume was $20 \mu \mathrm{L}$ and the column temperature was $30^{\circ} \mathrm{C}$. For MS analysis, ionization was conducted through positive-mode electrospray ionization (ESI+) with a full scan from $50 \mathrm{~m} / \mathrm{z}$ to $1000 \mathrm{~m} / \mathrm{z}$ under the following conditions: capillary potential $4 \mathrm{kV}$, cone voltage $35 \mathrm{~V}$, source temperature $110{ }^{\circ} \mathrm{C}$, desolvation temperature, $300{ }^{\circ} \mathrm{C}$.

\subsection{Fenton Homogenous reaction}

In recent years, advanced oxidation processes have been used to reduce pollutions caused by the presence of pharmaceutical compound residues in water without producing any secondary toxic contaminants in the environment (Garoma et al., 2010). Fenton Homogenous, firstly discovered in the 1890s. Fenton Homogenous reaction initiates with addition of both iron and hydrogen peroxide to remove various contaminants (Wang et al., 2010). Significant advantages of Fenton Homogenous method include high efficiency, biodegradability enhancement, simplicity in operation and flexibility (Biglarijoo et al., 2016). Conventional Fenton Homogenous process takes benefit of reagents $\left(\mathrm{H}_{2} \mathrm{O}_{2}\right.$ as oxidant and $\mathrm{FeSO}_{4} .7 \mathrm{H}_{2} \mathrm{O}$ as catalyst) and utilized to treat refractory wastewaters (Alver et al., 2015). Fenton Homogenous reaction steps are shown in Eqs. (1-5):

$$
\begin{aligned}
& \mathrm{Fe}^{2+}+\mathrm{H}_{2} \mathrm{O}_{2} \rightarrow \mathrm{Fe}^{3+}+\mathrm{OH}^{-}+\mathrm{OH}^{\circ} \\
& \mathrm{OH}^{\circ}+\mathrm{Fe}^{2+} \rightarrow \mathrm{OH}^{-}+\mathrm{Fe}^{3+} \\
& \mathrm{Fe}^{3+}+\mathrm{H}_{2} \mathrm{O}_{2} \rightarrow \mathrm{Fe}^{2+}+\mathrm{O}_{2} \mathrm{H}^{0}+\mathrm{H}^{+} \\
& \mathrm{OH}^{-}+\mathrm{H}_{2} \mathrm{O}_{2} \rightarrow \mathrm{HO}_{2}^{0}+\mathrm{H}^{+} \\
& \mathrm{H}_{2} \mathrm{O}_{2}+\mathrm{OH} \rightarrow \mathrm{H}_{2} \mathrm{O}+\mathrm{HO}_{2}
\end{aligned}
$$

\subsection{Experimental procedures}

A stock standard solution of CIP (500 mg/l) was prepared with dissolving $0.5 \mathrm{~g}$ of CIP in $1000 \mathrm{~mL}$ of distilled water. Other concentrations were prepared by appropriate dilution of the stock solution with distilled water. The degradation tests were performed in a beaker containing $100 \mathrm{~mL}$ of CIP solution at the designed concentration. Then, the required mass of ferrous sulfate was added. The Fenton Homogenous reaction was initiated by adding the required volume of hydrogen peroxide $\left(\mathrm{H}_{2} \mathrm{O}_{2}\right)$. The mixture was retained at a constant stirring of $120 \mathrm{rpm}$ at room temperature. The $\mathrm{pH}$ of the solution was adjusted to 3 by addition of $\mathrm{H}_{2} \mathrm{SO}_{4}(1 \mathrm{M})$ or $\mathrm{NaOH}(1 \mathrm{M})$.

\subsection{Process analysis}

Solution of CIP showed the maximum absorption peak at $275 \mathrm{~nm}$ when scanning the wave length range of 190- 400 $\mathrm{nm}$ using distilled water and Super acid $\left(\mathrm{Fe}^{2+}, \mathrm{H}_{2} \mathrm{O}_{2}\right)$ as blank. Then, concentrations of CIP were determined using a spectrophotometer at an absorbance of $275 \mathrm{~nm}$. Prior to the measurements, a calibration curve was achieved using standard CIP solution with known concentrations. $\mathrm{pH}$ measurements of solutions was done using a WTW (340i; WTW, Germany) pH meter. Efficiency percentage (De\%) was determined using:

$$
\operatorname{De}(\%)=\frac{C_{i}-C_{f}}{C_{i}} \times 100
$$

Where De is the degradation efficiency (\%), $C_{f}$ is the final CIP concentration, and $C_{i}$ is its initial concentration in the solution.

\subsection{Linearity}

For determine the calibration curve, samples were prepared with different CIP concentrations and their absorptions were measured (Table 2).

Table 2. Calibration data with nine concentrations and their corresponding absorbance values

\begin{tabular}{cc}
\hline Concentration $(\mathbf{m g} / \mathbf{l})$ & Absorbance $(\mathrm{Au})$ \\
\hline 1 & 0.10 \\
\hline 2 & 0.20 \\
\hline 3 & 0.33 \\
\hline 4 & 0.40 \\
\hline 5 & 0.50 \\
\hline 6 & 0.59 \\
\hline 7 & 0.65 \\
\hline 8 & 0.72 \\
\hline 9 & 0.82 \\
\hline
\end{tabular}

The obtained linear calibation curve, with a high correlation coefficient of $R^{2}=0.9932$. The equation for the curve is $Y=0.0882 X+0.0376$ where $Y$ is the absorbance (Au) and $X$ is the concentration in $\mathrm{mg} / \mathrm{l}$.

\subsection{Design of experimental (DOE) and statistical analyses}

A statistical methodology was determined for optimize the Fenton Homogenous process. In a $2^{f}$ factorial experimental design, $f$ factors are each varied at two levels. For a given combination of the $f$ factors, more than one test may be performed. Therefore, the total number of tests is given as: $N=2^{f}+C$, where $C$ represents the number of centerpoint measurements used to test the low-to-high range. Center points are simply experimental runs where $X^{\prime}$ s are set halfway in between (i.e., in the center of) the low and high settings (Elhalil et al., 2016). In the present work 
$N=17,(f=4, C=1)$. The polynomial equation based on the

first-order model with four parameters $\left(X_{1}, X_{2}, X_{3}\right.$ and

$X_{4}$ ) and their interaction terms may be given as:

$D e=b_{0}+b_{1} x_{1}+b_{2} x_{2}+b_{3} x_{3}+b_{4} x_{4}+b_{12} x_{1} x_{2}+b_{13} x_{1} x_{3}+b_{14} x_{1} x_{4}+b_{23} x_{2} x_{3}+b_{24} x_{2} x_{4}+b_{34} x_{3} x_{4}+b_{123} x_{1} x_{2} x_{3}+b_{134} x_{1} x_{3} x_{4}+b_{234} x_{2} x_{3} x_{4}$

As mentioned, the influence of four main parameters at a $\mathrm{PH}$ of $\sim 3$ was studied in the present research; concentration of $\operatorname{CIP}\left(X_{1}\right)$, ferrous ions $\left(X_{2}\right)$, hydrogen peroxide $\left(X_{3}\right)$, and time $\left(X_{4}\right)$. Suitable experimental values measured during pre-tests in a Fenton Homogenous process $\left(\mathrm{Fe}^{2+} / \mathrm{H}_{2} \mathrm{O}_{2}\right)$ for degradation of Ciprofloxacin in aqueous solution are shown in Table 3. The range of these parameters was selected according to literature and preliminary experiments (Elhalil et al., 2016).

Results were analyzed with 95\% confidence intervals using JMP ${ }^{\circledR} 11.0 .1$ statistical discovery software from Statistical Analysis Systems (SAS).

Table 3. Suitable experimental values for the independent variables

\begin{tabular}{|c|c|c|c|c|}
\hline \multirow[b]{2}{*}{ Coded symbol } & \multirow[b]{2}{*}{ Experimental variable (unit) } & \multicolumn{3}{|c|}{ Coded values } \\
\hline & & $\begin{array}{c}\text { Min value } \\
(-1)\end{array}$ & $\begin{array}{c}\text { Central point } \\
\text { (0) }\end{array}$ & $\begin{array}{c}\text { Max value } \\
(+1)\end{array}$ \\
\hline$X_{1}$ & Concentration of Ciprofloxacin (mg/l) & 10 & 45 & 80 \\
\hline$X_{2}$ & Concentration of ferrous ions $\left(\mathrm{mM}^{*}\right)$ & 5 & 7.5 & 10 \\
\hline$X_{3}$ & Concentration of hydrogen peroxide $\left(\mathrm{mM}^{*}\right)$ & 25.6 & 38.4 & 51.2 \\
\hline$X_{4}$ & Time (min) & 15 & 30 & 45 \\
\hline
\end{tabular}

${ }^{*} m M=m i l i M o l a r$

\section{Results and discussion}

\subsection{Degradation efficiencies}

The experimental matrix designed by Full factorial method, coded and real variable, and degradation efficiencies are all shown in Table 4. Two replications were used for each sample and their mean are presented in this table. As shown, the highest and lowest efficiency was observed at experimental no. 13 and no. 5 respectively. Apparently, CIP concentration and $\mathrm{H}_{2} \mathrm{O}_{2}$ concentration as a strong oxidizer had the highest influence on CIP degradation.

Table 4. The experimental matrix designed by Full factorial method, variables, and efficiencies

\begin{tabular}{|c|c|c|c|c|c|c|c|c|c|c|c|c|}
\hline \multirow[b]{2}{*}{ Experiment } & \multicolumn{4}{|c|}{ Coded variable } & \multicolumn{4}{|c|}{ Actual variable } & \multirow[b]{2}{*}{$\begin{array}{c}\text { First } \\
\text { run }\end{array}$} & \multirow{2}{*}{$\begin{array}{l}\text { Second } \\
\text { run }\end{array}$} & \multirow{2}{*}{$\begin{array}{c}\text { De* }^{*}(\%) \\
\text { (Average of } \\
\text { two runs) }\end{array}$} & \multirow{2}{*}{$\begin{array}{c}\text { Predicted } \\
\text { De (\%) }\end{array}$} \\
\hline & $X_{1}$ & $x_{2}$ & $x_{3}$ & $X_{4}$ & {$[\mathrm{CIP}]$} & {$\left[\mathrm{Fe}^{2+}\right]$} & {$\left[\mathrm{H}_{2} \mathrm{O}_{2}\right]$} & [Time] & & & & \\
\hline 1 & -1 & 1 & 1 & -1 & 10 & 10 & 51.2 & 15 & 65.8 & 68.2 & 67.1 & 54.0 \\
\hline 2 & 1 & 1 & 1 & 1 & 80 & 10 & 51.2 & 45 & 50.8 & 60.6 & 55.7 & 58.0 \\
\hline 3 & -1 & 1 & 1 & 1 & 10 & 10 & 51.2 & 45 & 60 & 76 & 68 & 64.0 \\
\hline 4 & 0 & 0 & 0 & 0 & 45 & 7.5 & 38.4 & 30 & 52.1 & 56.1 & 54.1 & 55.4 \\
\hline 5 & 1 & -1 & -1 & -1 & 80 & 5 & 25.6 & 15 & 25.1 & 33.1 & 29.1 & 35.2 \\
\hline 6 & -1 & 1 & -1 & -1 & 10 & 10 & 25.6 & 15 & 48.3 & 52.3 & 50.3 & 51.0 \\
\hline 7 & -1 & -1 & -1 & -1 & 10 & 5 & 25.6 & 15 & 65 & 67 & 66.0 & 67.0 \\
\hline 8 & 1 & -1 & 1 & -1 & 80 & 5 & 51.2 & 15 & 55.2 & 59.2 & 57.2 & 56.6 \\
\hline 9 & -1 & -1 & 1 & 1 & 10 & 5 & 51.2 & 45 & 69 & 76 & 72.5 & 71.8 \\
\hline 10 & 1 & 1 & -1 & -1 & 80 & 10 & 25.6 & 15 & 55.4 & 57.4 & 56.4 & 51.0 \\
\hline 11 & -1 & -1 & 1 & -1 & 10 & 5 & 51.2 & 15 & 53 & 55 & 54.0 & 50.5 \\
\hline 12 & 1 & 1 & -1 & 1 & 80 & 10 & 25.6 & 45 & 57.1 & 67.1 & 62.12 & 61.0 \\
\hline 13 & -1 & -1 & -1 & 1 & 10 & 5 & 25.6 & 45 & 76 & 80 & 76 & 68.0 \\
\hline 14 & 1 & -1 & 1 & 1 & 80 & 5 & 51.2 & 45 & 55.1 & 61.1 & 58.1 & 55.0 \\
\hline 15 & 1 & -1 & -1 & 1 & 80 & 5 & 25.6 & 45 & 33.8 & 35.8 & 34.8 & 34.0 \\
\hline 16 & -1 & 1 & -1 & 1 & 10 & 10 & 25.6 & 45 & 43 & 55 & 49.0 & 52.0 \\
\hline 17 & 1 & 1 & 1 & -1 & 80 & 10 & 51.2 & 15 & 57.4 & 47 & 52.2 & 48.0 \\
\hline
\end{tabular}

${ }^{*}$ De: Degradation efficiency (\%)

By substituting the coefficients bi in Eq. (8), De model can be expressed as: 


\subsection{Main effects}

Based on Equation (8), it was noted that a parameter concentration of CIP is negative; means that negative effects on the response. Other factors, concentrations of CIP, ferrous ion, hydrogen peroxide and the time having positive effects means that high-level parameters are more important in the contaminants removal. It is known that reduction of the contaminant is basically proportional to $\mathrm{H}_{2} \mathrm{O}_{2}$ and its breakdown to $\mathrm{OH}^{\circ}$. Any extra Fe ion would react with the hydroxyl radical and reduce efficiency of the procedure in Equation (9) (Oliveira et al., 2006; Joseph et al., 2000).

$$
\mathrm{Fe}^{2+}+\mathrm{OH}^{\circ} \rightarrow \mathrm{Fe}^{3+}+\mathrm{HO}^{-}
$$

In concentrations greater than the optimal amount occurred decomposition of hydrogen peroxide into oxygen and water. Therefore, it may be concluded that too high a concentration of $\mathrm{H}_{2} \mathrm{O}_{2}$ acts as an inhibitor for the formation of $\mathrm{OH}^{\circ}$, and consequently, reduce efficiency of the process; a phenomenon reported in the literature as well (Fu et al., 2007).

\subsection{Interactions among factors}

Interactions among parameters are shown at low and high levels of all parameters on Fig. 2. The figure indicates that most important interactions exist among $\left(X_{1}\right.$ and $\left.X_{2}\right)$, $\left(X_{2}\right.$ and $\left.X_{1}, X_{3}\right)$ and $\left(X_{4}\right.$ and $\left.X_{1}, X_{3}\right)$. For example, the box associated with $\mathrm{Fe}^{2+}$ and $\mathrm{H}_{2} \mathrm{O}_{2}$ considers the interaction of low and high levels of the rate variable $\left(\mathrm{Fe}^{2+}\right)$ for both levels of $\mathrm{H}_{2} \mathrm{O}_{2}(-1$ and 1$)$. The pink line represents the low and the blue line the high level of $\mathrm{H}_{2} \mathrm{O}_{2}$. The two lines cross, indicating that there is an interaction among $\mathrm{Fe}^{2+}$ and $\mathrm{H}_{2} \mathrm{O}_{2}$. Parallel and non-crossing lines indicate that there is no interaction among considered parameters.

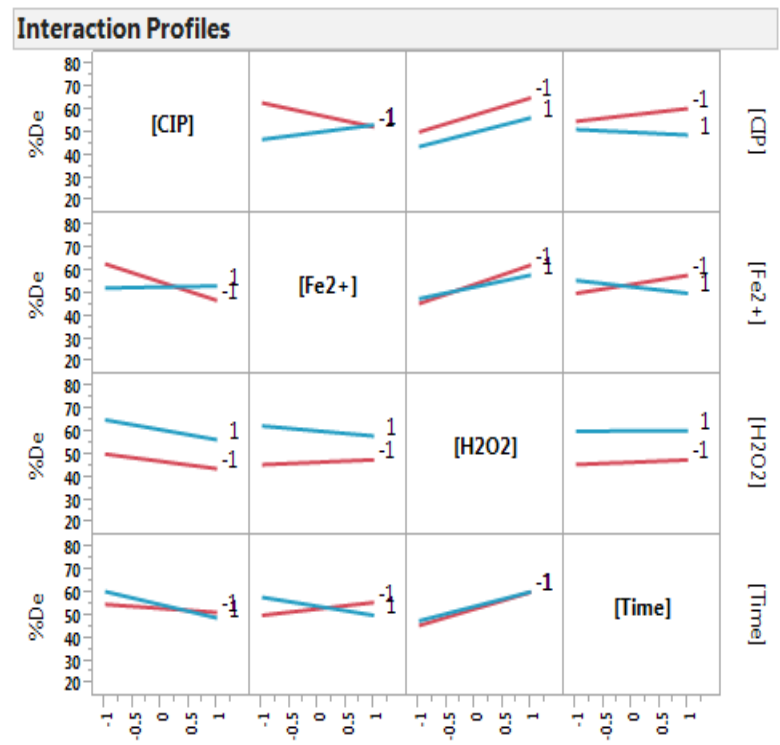

Figure 2. Plots for interactions among parameters affecting CIP degradation efficiency (De)

A 3D plot of the response surface (degradation efficiency) for every two interacting parameters may be drawn at the optimal condition. Such surfaces for $\mathrm{CIP}-\mathrm{Fe}^{2+}, \mathrm{CIP}-\mathrm{H}_{2} \mathrm{O}_{2}$ and $\mathrm{Fe}^{2+}-\mathrm{H}_{2} \mathrm{O}_{2}$ are shown on Figs. 3, 4, and 5 respectively. As shown on Fig. 3, degradation efficiency increases with decreasing CIP and/or decreasing $\mathrm{Fe}^{2+}$ concentrations. However, as shown on Fig. 4, degradation efficiency increases with decreasing $\mathrm{CIP}$ but with increasing $\mathrm{H}_{2} \mathrm{O}_{2}$ concentrations. Fig. 5, reflects a somewhat similar conclusion where response surface increases with decreasing $\mathrm{Fe}^{2+}$ and/or increasing $\mathrm{H}_{2} \mathrm{O}_{2}$.

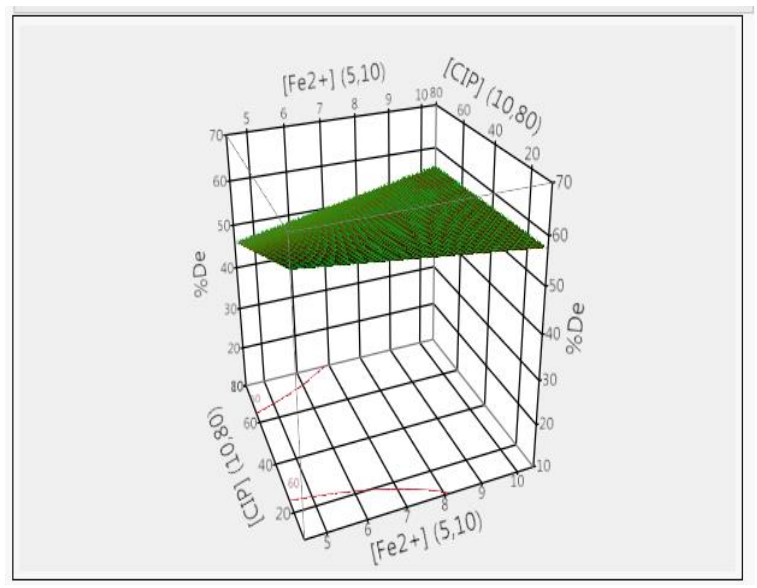

Figure 3. 3D plot of the response surface as a function of $[\mathrm{CIP}]$ and $\left[\mathrm{Fe}^{2+}\right]\left(\left[\mathrm{H}_{2} \mathrm{O}_{2}\right]=26.5 \mathrm{mM}\right.$; Time $\left.=45 \mathrm{~min}\right)$

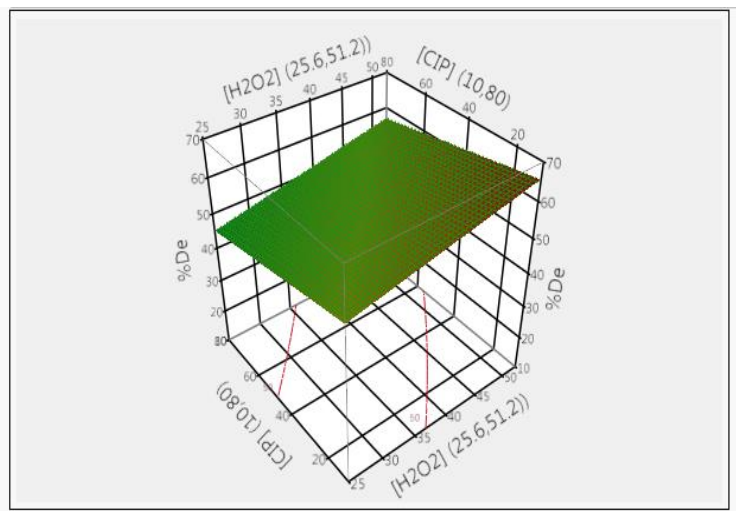

Figure 4. 3D plot of the response surface as a function of $[\mathrm{CIP}]$ and $\left[\mathrm{H}_{2} \mathrm{O}_{2}\right]\left(\left[\mathrm{Fe}^{2+}\right]=5 \mathrm{mg} / \mathrm{l}\right.$; Time $\left.=45 \mathrm{~min}\right)$

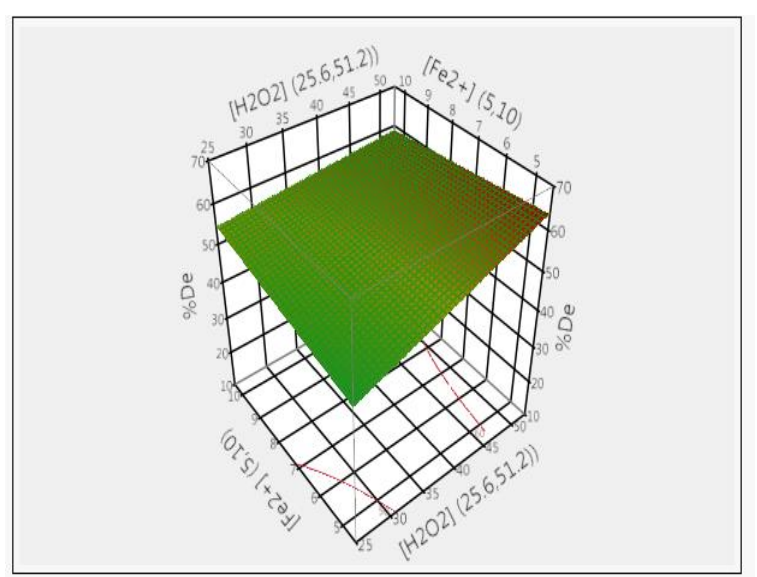

Figure 5. 3D plot of the response surface as a function of $\left[\mathrm{H}_{2} \mathrm{O}_{2}\right]$ and $\left[\mathrm{Fe}^{2+}\right]([\mathrm{CIP}]=10 \mathrm{mg} / \mathrm{l}$; Time= $45 \mathrm{~min})$ 


\subsection{Analysis of variance (ANOVA)}

Assess the accuracy of the model is investigated with the analysis of variance (ANOVA) based on a Full factorial design, and the results are presented in Table 5 . The main and interacting effects of each factor having P-values less than 0.05 are considered as potentially notable. In other words, the low P-value indices (shown in red) correspond to significant factors such as [CIP], interactions of $\left[\mathrm{Fe}^{2+}\right]$, $\left[\mathrm{H}_{2} \mathrm{O}_{2}\right]$ and [time]. Such factors also have high t-ratios which exceed the blue line threshold on the Table. Considering only the main factors, it may be concluded concentration of $\mathrm{CIP}, \mathrm{H}_{2} \mathrm{O}_{2}$, interactions of $\mathrm{Fe}^{2+}$ and time are important, respectively.

Table 5. ANOVA test results for important factors affecting degradation percentage based on a Full factorial design

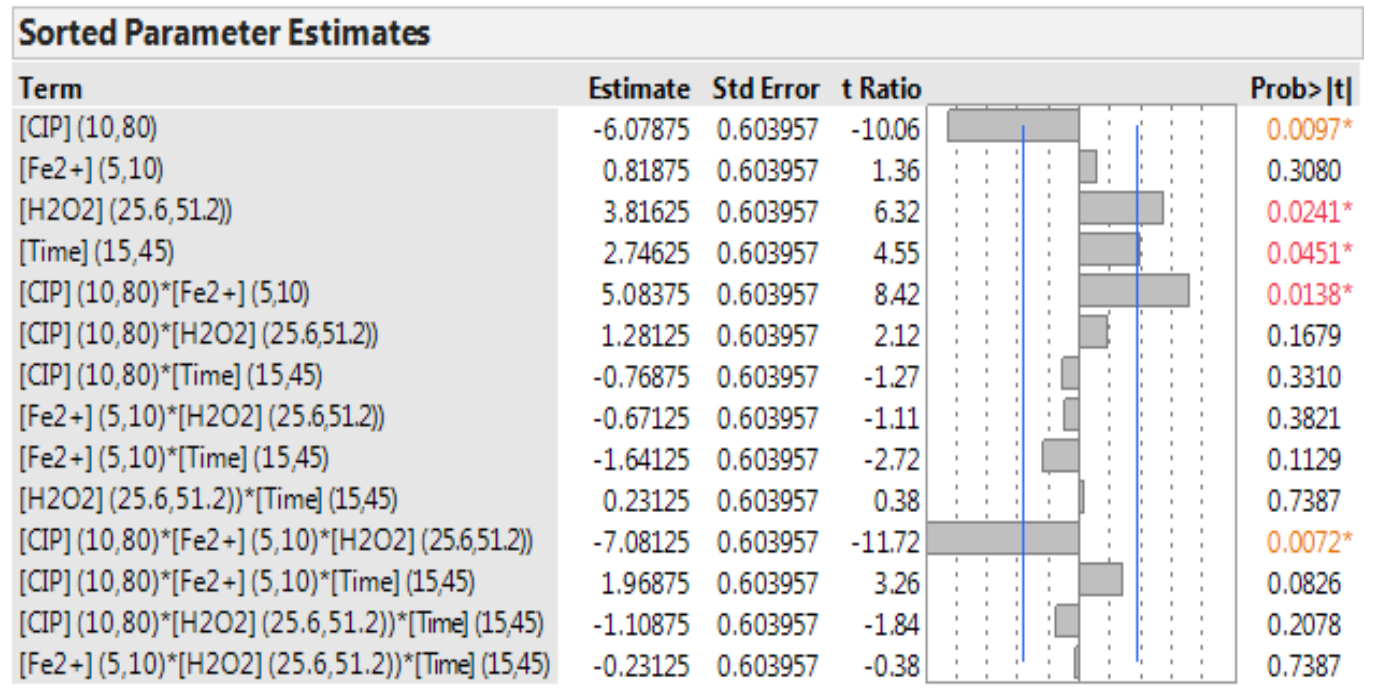

\subsection{Validity of the model}

Observed efficiencies (De) for degradation of CIP were plotted against predicted ones (Fig. 6.), reflecting an excellent match. Analysis of variance (ANOVA) based on Full factorial design is also shown on Table 6. As shown, predicted values match the experimental ones well with an $R^{2}=0.996$, indicating that $99.6 \%$ of the variations for De (\%) are explained by the independent variables. Adjusted $R^{2}$ $\left(\operatorname{Adj}-R^{2}\right)$, a modified version of R-squared adjusted for the number of predictors in the model, may be more suitable for comparing models with different numbers of independent variables (Guoqiang et al., 2017). Also, F-ratio is notable in Table 6, indicating that the model adopted in this study (full factorial design) is acceptable and validated.

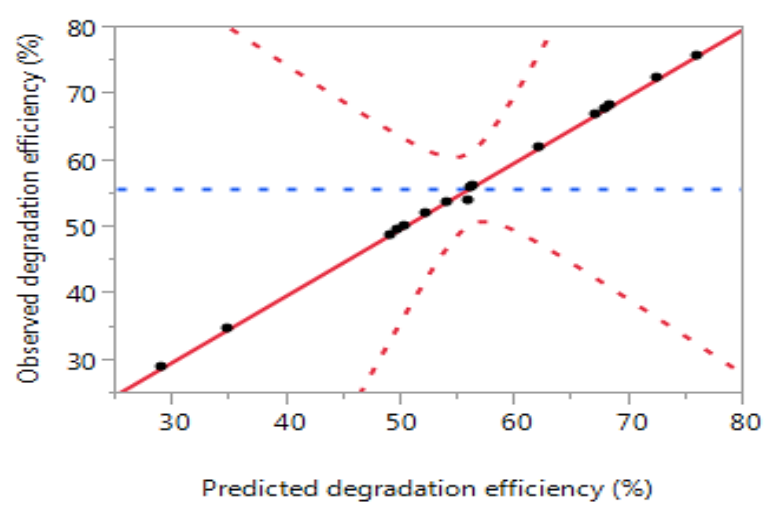

Figure 6. Predicted vs. observed efficiencies for degradation of Ciprofloxacin

Table 6. Analysis of variance (ANOVA) based on Full factorial design results

\begin{tabular}{|c|c|c|c|c|}
\hline Source & Degree of freedom & Sum of squares & Mean squares & F- Ratio \\
\hline Model & 14 & 2342.1 & 167.2 & 36.22 \\
\hline Pure Error & 2 & 9.23 & 1.653 & - \\
\hline C. Total & 16 & 2351.3 & - & - \\
\hline $\mathrm{R}^{2}=0.996$ & $\mathrm{R}^{2}{ }_{\mathrm{adj}}=0.968$ & - & - & - \\
\hline
\end{tabular}

\subsection{Identification of primary intermediates}

To illuminate the degradation mechanism of CIP in the Homogeneous Fenton process system and thus to show a possible reaction pathway, a mass spectroscopy study was carried out to determine the intermediates in aqueous solution. The intermediates during CIP degradation detected by the peaks formed using HPLC-MS. Table 7 summarizes molecular structure and $\mathrm{m} / \mathrm{z}$ values of four primary intermediates compound identified by this technique.

A noteworthy alternative to completing oxidation through chemical methods is the utilize of a chemical pre-treatment process for the conversion of biodegradable acids initially through biodegradation reactions, also to broken into biodegradable intermediates, and then the biological 
oxidation of these intermediates to simpler compounds such as biomass and water.

For example, organic macromolecules, such as resistant organic compounds of soluble in water, by chemical oxidation might break into smaller intermediate compounds (such as short-chain organic acids) that are easily degraded from the original molecules, so the biological oxidation rate increases with decreasing molecular size (Abbasi, 2009).
It should be noted that, complete degradation of these intermediates to water and $\mathrm{Co} 2$ (carbon dioxide) is difficult because of decreasing division rate of $\mathrm{C}-\mathrm{C}$ bond by decreasing molecular size of them. So, chemical oxidation and biological treatment as pre-treatment and posttreatment, respectively for resistant organic compounds are practically useful (Mantzavinos and Psillakis, 2004). Results of biodegradable intermediates assessed based on $\mathrm{BOD}_{5} / \mathrm{COD}$ ratio shows that Fenton Homogenous method can be utilized for greater improvements of biodegradability which enhanced from zero to 0.32 .

Table 7. Identification of the CIP degradation intermediates by HPLC-MS

\begin{tabular}{|c|c|c|c|}
\hline Compound & Retention time (min) & $\mathrm{m} / \mathrm{z}$ & Proposed structure \\
\hline $\mathrm{CIP}$ & 2.56 & 332 & \\
\hline 1 & 2.83 & 330 & \\
\hline 2 & 3.12 & 334 & \\
\hline 3 & 3.15 & 287 & \\
\hline 4 & 3.21 & 263 & \\
\hline
\end{tabular}

We should also note that there may be other intermediate products as well. Due to well-known intermediate products, we concluded that the proposed method can be accepted for complex compound organic compounds as a pre-treatment method.

\section{Conclusions}

Full factorial method, the only means to completely and systematically study interactions between factors in addition to identifying significant ones, utilized to design a test and determine optimum conditions for CIP degradation by Fenton Homogenous method. It is known that one-factor-at-a-time experiments (where each factor is investigated separately by keeping all the remaining factors constant) do not reveal the interaction effects between the factors. Full factorial design focused on relationships among process variables to maximize the impact and determine the optimal conditions for better degradation of CIP. The experimental system used in present study was discontinuous, and concentration of the 
antibiotic was detected using UV-visible spectrophotometric as opposed to other devices that had been used in previous studies. The use of this device has important advantages such as simplicity, speed, high sensitivity, and low cost per analysis.

Based on the results, CIP degradation indeed occurred with Fenton Homogenous process, and hence, it may be utilized as a pretreatment process for antibiotics in aqueous solution. Statistical analysis results show that optimal conditions for the highest CIP degradation in polluted water are $\mathrm{pH}=3 ;[\mathrm{CIP}]=10 \mathrm{mg} / \mathrm{l} ;\left[\mathrm{Fe}^{2+}\right]=5 \mathrm{mM} ;\left[\mathrm{H}_{2} \mathrm{O}_{2}\right]=25.6$ $\mathrm{mM}$, where a maximum degradation efficiency of $76 \%$ occurred in $45 \mathrm{~min}$. An excellent correlation between predicted and observed degradation efficiencies was obtained, confirming validity and practicability of the adopted model with $\mathrm{R}^{2}=0.996$ and $\mathrm{Adj}-\mathrm{R}^{2}=0.968$. In addition, results show that all parameters were important in the analysis and degradation of the antibiotic, however with different levels of importance, ranking from the highest (initial concentration of CIP and concentration of $\mathrm{H}_{2} \mathrm{O}_{2}$ ) to the lowest important ones (concentration of $\mathrm{Fe}^{2+}$ and time). The result of $\mathrm{BOD}_{5} / \mathrm{COD}$ ratio shown that biodegradability enhanced from zero to 0.32 , demonstrating the effluent Fenton Homogenous process can be applied to biological treatment.

\section{Acknowledgement}

Authors gratefully acknowledge Shiraz Serum Pharmaceutical Company, Shiraz, Iran, for providing Ciprofloxacin samples.

\section{References}

Abbassi B.E. (2009), Chemical Treatment and Enhancement of Bioavailability of Olive Mill Wastewater, Water Qual. Res. J. Can., 44(3), 307-312.

Abdennouri M., Galadi A., Barka N., Baâlala M., Nohair K., Elkrati M., Sadiq M. and Bensitel M. (2015), Synthesis, characterization and photocatalytic activity by para-chloro toluene photo oxidation of tinoxide films deposited on Pyrexglass substrates, Phys. Chem. News., 4, 126-130.

Alver A., Bastürk E., Kilic A. and Karatas M. (2015), Biodegradability of olive-oil mill effluent through 448 advanced oxidation process, Process. Saf. Environ., 98, 319324.

Arenas L.T., Lima E.C., Santos A.A.D., Vaghetti J.C.P., Coasta T.M.H. and Benvenutti E.V. (2006), Use of statistical design of experiments to evaluate the sorption capacity of 1,4 diazoniabicycle $[2,2,2]$ octane silica chloride for $\operatorname{Cr}(\mathrm{VI})$ adsorption, Colloids Surf. A: Physiochem Eng. Asp., 297, 243248.

Baeissa E.S. (2016), Photocatalytic degradation of malachite green dye using $\mathrm{Au} / \mathrm{NaNO}_{3}$ nanoparticles, J. Alloy. Compd., 672, 564-570.

Barka N., Abdennouri M., Boussaoud A., Galadi A., Baâlala M., Bensitel M., Sahibed-Dine A. and Nohair K. and Sadiq M. (2014), Full factorial experimental design applied to oxalic acid photocatalytic degradation in $\mathrm{TiO}_{2}$ aqueous suspension, Arab. J. Chem., 7, 752-757.

Biglarijoo N., Mirbagheri S.A., Ehteshami M. and Moavenzadeh Ghaznavi S. (2016), Optimization of Fenton process using response surface methodology and analytic hierarchy process for landfill leachate treatment, Process Safety and
Environment

Protection,

http://dx.doi.org/doi:10.1016/j.psep.2016.08.019.

Bobu M., Yediler A., Siminiceanu I. and Schulte-Hostede S. (2008), Degradation studies of Ciprofloxacin on a pillared iron catalyst, Appl. Catal. B: Environ, 83, 15-23.

Bouasla C., Samar M.E. and Ismail F. (2010), Degradation of methyl violet 6 B dyes by the Fenton process, Desalination, 254, 35-41.

Capriotti A.L., Cavaliere C., Piovesana S., Samperi R. and Laganà A. (2012), Multiclass screening method based on solvent extraction and liquid chromatography-tandem mass spectrometry for the determination of antimicrobials and mycotoxins in egg, J. Chromatogr., 1268, 84-90

Carlucci G. (1998), Analysis of Fluoroquinolonein biological fluids by high-performance liquid chromatography, J. Chromatogr, 812, 343-367.

De Bel E., Dewulf J., Witte BD., Van Langenhove H. and Janssen C. (2009), Influence of $\mathrm{pH}$ on the sonolysis of Ciprofloxacin: Biodegradability, ecotoxicity and antibiotic activity of its degradation products, Chemosphere, 77, 291-295. DOI: 10.1016/j.chemosphere.

Dirany A., Sires I., Oturan N. and Oturan M.A. (2010), Electrochemical abatement of the antibiotic sulfamethoxazole from water, Chemosphere, 81, 594-602.

Elhalil A., Tounsadi H., Elmoubarki R., Mahjoubi F.Z., Farnane M., Sadiq M., Abdennouri M., Qourzal S. and Bark N. (2016), Factorial experimental design for the optimization of catalytic degradation of malachite green dye in aqueous solution by Fenton process, Water Resources and Industry, 15, 41-48

Fu J.F., Zhao Y.Q. and Wu Q.L. (2007), Optimizing photoelectron catalytic oxidation of fulvic acid using response surface methodology, J. Hazard Mater., 144, 499-505.

Gagnon C., Lajeunesse A., Cejka P., Gagne F. and Hausler R. (2008), Degradation of selected acidic and neutral pharmaceutical products in a primary-treated wastewater by disinfection processes, Ozone-Sci. Eng., 30, 387-392.

Garoma T., Umamaheshwar S.K. and Mumper A. (2010), Removal of sulfadiazine, sulfamethizole, sulfamethoxazole, and sulfathiazole from aqueous solution by ozonation, Chemosphere, 79, 814-20.

Giri A.S. and Golder A.K. (2014), Ciprofloxacin degradation from aqueous solution by Fenton oxidation: reaction kinetics and degradation mechanisms, RSC Adv., 6738-6745. DOI: 10.1039/c3ra45709e.

Guo H.G., Gao N.Y., Chu W.H., Li L., Zhang Y.J., Gu J.S. and Gu Y.L. (2013), Photo chemical degradation of Ciprofloxacin in UV and $\mathrm{UV} / \mathrm{H}_{2} \mathrm{O}_{2}$ process: kinetics, parameters, and products, Environ Sci Pollut. Res., 20, 3202-3213.

Guoqiang G., Juan L., Zhixi Z., Ziran Y., Conglu Z. and Xiaohong H. (2017), A novel magnetic nanoscaled $\mathrm{Fe}_{3} \mathrm{O}_{4} / \mathrm{CeO}_{2}$ composite prepared by oxidation-precipitation process and its application for degradation of orange $\mathrm{G}$ in aqueous solution as Fenton-like heterogeneous catalyst, Chemosphere, 168, 254-263.

Han R.W., Zheng N., Yu Z.N., Wang J., Xu X.M., Qu X.Y., Li S.L., Zhang Y.D. and Wang J.Q. (2015), Simultaneous determination of 38 veterinary antibiotic residues in raw milk by UPLC-MS/MS, Food Chem., 181, 119-126.

Hassani A., Khataeeb A. and Karaca S. (2015), Photocatalytic degradation of Ciprofloxacin by synthesized $\mathrm{TiO} 2$ nanoparticles on montmorillonite: Effect of operation 
parameters and artificial neural network modeling, Journal of Molecular Catalysis A: Chemical, 409, 149-161.

Jiang W.T., Chang P.H., Wang Y.S., Tsai Y., Jean J.S., Li Z. and Krukowski K. (2015), Sorption and desorption of tetracycline on layered manganese dioxide birnessite, Int. J. Environ Sci Technol., 12, 1695-1704. DOI: 10.1007/s13762-014-0547-6.

Joseph J.M., Destaillats H., Hung H.M. and Hoffmann M.R. (2000), The sonochemical degradation of azo benzene and related azo dyes: Rate enhancements via Fenton's reactions, J. Phys Chem A., 104, 301-307.

Kamberi M., Tsutsumi K., Kotegawa T., Nakamura K. and Nakano K.S. (1998), Analysis of Fluoroquinolonein biological fluids by high-performance liquid chromatography, Clin. Chem., 44, 1251-1255.

Kassab N.M., Singh A.K., Kedor-Hackmam E.R.M. and Santoro M.M. (2005), Quantitative determination of Ciprofloxacin and norfloxacin in pharmaceutical preparations by high performance liquid chromatography, Brazilian Journal of Pharmaceutical Sciences, 41(4), 507-513.

Krzek J., Hubicka U. and Szczepańiczyk J. (2005), Highperformance thin-layer chromatography with densitometry for the determination of Ciprofloxacin and impurities in drugs, Journal of AOAC International, 88, 1530-6.

Mantzavinos D. and Psillakis E. (2004), Enhancement of biodegradability of industrial wastewaters by chemical oxidation pre-treatment, J Chem Technol Biotechnol, 79, 431454.

Maya M.T., Goncalves N.J., Silva N.B. and Morais J.A. (2001), Simple High-Performance Liquid Chromatographic Assay for the Determination of Ciprofloxacin in Human Plasma with Ultraviolet Detection, Journal of Chromatography B: Biomedical Sciences and Applications, 755, 305-309. http://dx.doi.org/10.1016/S0378-4347(01)00126-8.

Oliveira R., Almeida M.F., Santos L. and Madeira L.M. (2006), Experimental design of 2,4-dichlorophenol oxidation by Fenton's reaction, Ind. Eng. Chem. Res., 45, 1266-1276.

Ou H., Ye J., Ma S., Wei C., Gao N. and He J. (2016), Degradation of Ciprofloxacin by UV and UV/ $\mathrm{H}_{2} \mathrm{O}_{2}$ via multiple-wavelength ultraviolet light-emitting diodes: Effectiveness, intermediates and antibacterial activity, Chemical Engineering Journal, 289, 391-401.

Pera-Titus M., Garcí a-Molina V., Baños M.A., Giménez J. and Esplugas S. (2004), Degradation of chlorophenols by means of advanced oxidation processes: a general review, Appl. Catal B: Environ., 47, 219-256.

Salari M., Rakhshandehroo G.R. and Nikoo M.R. (2018), Degradation of ciprofloxacin antibiotic by Homogeneous Fenton oxidation: Hybrid AHP-PROMETHEE method, optimization, biodegradability, improvement and identification of oxidized byproducts, Chemosphere, 206, 157-167.

Salari M., Rakhshandehroo G.R. and Nikoo M.R. (2018), Multiobjective optimization of ciprofloxacin antibiotic removal from an aqueous phase with grey taguchi method, Journal of Water and Health, (In press), DOI: 10.2166/wh.2018.247.

Wang C.T., Chou W.L., Chung M.H. and Kuo Y.M. (2010), COD removal from real dyeing wastewater by electro-Fenton technology using an activated carbon fiber cathode, Desalination, 253, 129-34.

Wang H.L., Liang W.Z., Zhang Q.A. and Jiang W.F. (2010), Solarlight-assisted Fenton oxidation of 2,4-dinitrophenol (DNP) using $\mathrm{Al}_{2} \mathrm{O}_{3}$ (III)-5- sulfo salicylic acid (ssal) complex as catalyst, Chem. Eng. J., 164, 115-120.

Wright D.H., Herman V.K., Konstantinides F.N. and Rotschafer J.C. (2000), Determination of quinoline antibiotics in growth media by reversed-phase high-performance liquid chromatography, J. Chromatogr. B., 709, 97-104.

Wynnae O. (2003), Antibiotics in the environment TESC 422 case study paper, Available at: http://www.Consciouschoiccom/health/antibiotics 1207.html. Updated in.

Xiong J., Kurade M.B., Rae Kim J., Roh H.S. and Jeon B.H. (2017), Ciprofloxacin toxicity and its Co-metabolic removal by a freshwater microalga Chlamydomonas Mexicana, Journal of Hazardous Materials, 323, 212-219.

Yorke J.C. and Froc P. (2000), Quantitation of nine quinolones in chicken tissues by high-performance liquid chromatography with fluorescence detection, J. Chromatogr. A., 882, 63-77.

Zhang X., Li R., Jia M., Wang S., Huang Y. and Chen C. (2015), Degradation of ciprofloxacin in aqueous bismuth oxybromide $(\mathrm{BiOBr})$ suspensions under visible light irradiation: $\mathrm{A}$ direct hole oxidation pathway, Chemical Engineering Journal, 274, 290-297. 